\title{
STUDY OF MATERNAL AND FETAL OUTCOME IN PRETERM PREMATURE RUPTURE OF MEMBRANE
}

Padma Shukla', Meena Bhargava², Disha $^{3}$

\section{HOW TO CITE THIS ARTICLE:}

Padma Shukla, Meena Bhargava, Disha. "Study of Maternal and Fetal Outcome in Preterm Premature Rupture of Membrane". Journal of Evolution of Medical and Dental Sciences 2014; Vol. 3, Issue 07, February 17; Page: 1789-1795, DOI: $10.14260 /$ jemds/2014/2059

ABSTRACT: Premature rupture of membrane before 37 wks. gestation is known as preterm premature rupture of membrane (PPROM). Aim of this study is to apply recommended management in PPROM so as to have best maternal and fetal outcome and to study various maternal and neonatal complications and various neonatal morbidities in relation to gestation age (GA) and birth weight. METHOD: 200 patients with PPROM were included in the study. Maternal and fetal status closely monitored, cases were followed during delivery and postnatally, mode of delivery, total weight, APGAR score, maternal and fetal outcome recorded. Statistical analysis was done by using chi square test. RESULTS: $26.5 \%$ cases were PPROM remote from term and $73.5 \%$ cases were PPROM near term. PPROM nearer the term less was the latency. Out of 200 PPROM cases 171 delivered vaginally and 29 delivered by LSCS. Maternal morbidity was observed in 33 cases. In this study $95 \%$ live birth and 5\% were still birth. RDS was the commonest neonatal morbidities $32 \%$ followed by neonatal sepsis 20.0\%. CONCLUSION: Premature infant puts immense burden on the economy and health care resources of the country. Therefore, management of PPROM requires accurate diagnosis and evaluation of the risks and benefits of continued pregnancy or expeditious delivery.

KEYWORDS: Preterm Premature Rupture of Membrane (PPROM), Neonatal Death (NND), Neonatal Sepsis (NNS), Intraventricular Hemorrhage (IVH).

INTRODUCTION: Premature rupture of membrane (PROM) is the rupture of the fetal membranes before the onset of labor. In most cases this occurs near term, but when membrane rupture occurs before 37 weeks gestation it is known as preterm premature rupture of membrane (PPROM). It is one of the leading identifiable causes of pre-maturity. PPROM is a condition that occurs in $3 \%$ of all pregnancies and is responsible for approximately $30 \%$ of all preterm deliveries ${ }^{1}$. Eighty five percent of neonatal morbidity and mortality is result of prematurity. PPROM remote from term is associated with significant perinatal morbidity and mortality that decreases with advancing gestational age at delivery. Alternatively, PPROM near term with expeditious delivery of non-infected and nonasphyxiated infants is associated with a high likelihood of survival and a low risk of severe morbidity.

When PROM occurs remote from term, significant risks of morbidity and mortality are present for both the mother and fetus. Thus, the physician caring for the pregnant woman plays an important role in management and need to be familiar with potential complications and possible interventions to minimize risks and maximize the probability of the desired outcome.

There is an enhanced risk of cord compression/prolapse and infectious morbidity, particularly so if cesarean section becomes eventually necessary. Approximately two-thirds of the patients with PROM are delivered within the next 4 days and the rest within 1 week. The time between the rupture of membranes and onset of labor (latent period) may extend from hours to days, generally shorter the gestation period longer the latent period. 
At present our goals as far as the preventive aspects are concerned concentrate upon minimizing or avoiding the development of the most serious complication namely sepsis. It is recognized that the likelihood of sepsis increases as a function of time from the moment the fetal membranes rupture. Fetal infection may occur when maternal vital signs are normal. Moreover the question of the long term sequelae in the newborn to prolong exposure to intrauterine infection still needs to be answered. The fact that fetal and neonatal results should not be gauged by perinatal mortality rates only, but should include the ultimate outcome of the infants some months or a year or more following birth.

PROM is such a common and important event in obstetrics that it is surprising to find a tremendous divergence of opinion concerning its proper management. At the outset it can be said that as yet no one management strategy has emerged superior to all others.

MATERIAL AND METHODS: The present prospective study was conducted in the Department of Obstetrics and Gynecology, S.S. Medical College and associated Gandhi Memorial Hospital, Rewa. The study was conducted on spontaneous preterm premature rupture of membrane on 200 cases.

All patients from July 2010 to October 2011, who presented with preterm premature rupture of membrane before 37 completed weeks of gestation included in the study.

Detailed history regarding age, education and social status of patients and dietary habits of patients were recorded. Patients were classified into booked, partially booked/unbooked according to number of antenatal visits. The obstetric history included duration of gestation estimated by naegele's rule (1 $1^{\text {st }}$ day of LMP) and confirmed by recorded PV examination of $1^{\text {st }}$ trimester and any $1^{\text {st }} / 2^{\text {nd }}$ trimester sonography if available. Duration of leaking calculated from time since leaking started.

Detail past obstetric history of patient was recorded. An account was taken regarding duration of gestation of previous pregnancies, mode of their termination and outcome with a view to find out whether it was responsible for premature rupture of membrane (eg. incompetent OS, repeated miscarriage or malformation of fetus).

Complete physical examinations of patients were conducted. It included general examination, to note for any evidence of occult /overt infection and systemic examination was conducted to rule out possible causes of PPROM: e.g. pregnancy induced hypertension, heart diseases, respiratory diseases etc. Obstetric examination included a record of height of uterus, presentation of fetus, presence or absence of fetal heart sound, presence of liquor, presence of uterine contraction.

PPROM were confirmed if on speculum examination, there was amniotic fluid seen draining through the cervical OS along with reduced amniotic fluid index on ultrasound. In equivocal cases nitrazene test was performed for confirmation.

Laboratory investigation included blood group, hemoglobin percentage, total and differential white cell count and ESR. In cases of suspected infection high vaginal swab culture and sensitivity was sent.

All patients with PPROM were put on conservative management if no signs of infection were present. Active management was done if any sign of infection was present.

Administration of prophylactic antibiotics initially intravenous ampicillin 2gm followed by 1gm IV every 6 hourly for 24 hours followed by amoxicillin 250mg orally every 8 hourly for 10 days, 
and administration of betamethasone $12 \mathrm{mg}$ intramuscularly ( 2 doses 24 hours apart) in pregnancies less than 34 weeks.

Maternal and fetal status was closely monitored for development of chorioamnionitis, labor or fetal compromise. The criteria for maternal infection was temperature $>38^{\circ} \mathrm{C}$ with one or more of the following signs, uterine tenderness, fetal or maternal tachycardia or foul smelling amniotic fluid draining per vaginum in absence of any obvious reason for elevated temperature.

Expectant management was abandoned and delivery expedited if any of the following criteria were noted chorioamnionitis, active labor, fetal compromise, gestational age 36 weeks or more.

Patients were followed during labor, delivery and postnatally. Mode of delivery, fetal weight, APGAR score, and maternal and neonatal outcome were recorded including composite major neonatal morbidities (RDs, IVH, NEC, NNS, Pneumonitis) maternal infection morbidity (endometrium or chorioamnionitis) and neonatal and maternal length of stay.

The results were analyzed regarding their correlation with demographic and obstetrical variable along with mode of delivery low birth weight, perinatal morbidity and mortality and maternal morbidity. Statistical analysis was done by using chi square test.

RESULT: Among 11072 deliveries 200 women with PPROM identified so the incidence of PPROM was $1.8 \%$ out of which $26.5 \%$ cases were between $28-30$ weeks, $33.5 \%$ between $31-33$ weeks and $40.0 \%$ were between 34-36 weeks.

In this study maximum numbers of women 118 (59.0\%) were between 21-25 years and mean age was $23.52 \pm 3.70$ due to early marriages and short birth interval. Most of the patients included in study belong to low socioeconomic status. Out of 200 cases $50 \%$ cases were unbooked and $31 \%$ partially booked.

Incidence of PPROM was $50 \%$ in primigravida, $27.5 \%$ in gravida II and $23.0 \%$ in multi. History of previous preterm deliveries present in 37 (18.5\%) cases and 50 (25.0\%) women had history of abortion. Latent period which is the time from membrane rupture until delivery is inversely proportional to the gestational age at which PPROM occurred. 6.8\% cases with PROM at 2830 weeks had latency $\leq 24$ hours while $57.1 \%$ cases at same GA had latency $\leq 72$ hours. Similarly $68.18 \%$ cases at $34-36$ weeks had latency $\leq 24$ hours and $4.76 \%$ cases at same GA had latency $<72$ hours.

\begin{tabular}{|c|c|c|c|c|}
\hline S.No. & Latency & 28-30 wks. & 31-33 wks. & 34-36 wks. \\
\hline 1. & $\leq 24$ hrs. (44) & $3(6.8 \%)$ & $11(25 \%)$ & $30(68.18 \%)$ \\
\hline 2. & $25-48$ hrs. (82) & $8(9.8 \%)$ & $30(36.5 \%)$ & $44(53.6 \%)$ \\
\hline 3. & 49-72 hrs. (32) & $18(56.2 \%)$ & $10(31.2 \%)$ & $04(12.5 \%)$ \\
\hline 4. & $>72$ hrs. (42) & $24(57.1 \%)$ & $16(38 \%)$ & $02(4.76 \%)$ \\
\hline Total & 200 & 53 & 67 & 80 \\
\hline
\end{tabular}
$\chi 2=73.821$
Degree of freedom $=6$
$\mathrm{p}<0.0001$ Significant

In this study $85.5 \%$ had vaginal delivery while $14.5 \%$ delivered by cesarean section. There were no instrumental deliveries. Out of 200 cases 40 women had maternal complication, 5 (2.5\%) 
women with PPROM were admitted with chorioamnionitis. None of the patient developed chorioamnionitis while on expectant management. Abruption developed in 4\%; PPH in 3.0\% and puerperal pyrexia in $8.0 \%$. In present study risk of chorioamnionitis and abruption increased proportionally with latency. Maximum occurrence $60.0 \%$ of chorioamnionitis was in cases with latent period $>72$ hours. Similarly risk of abruption increased (50.0\%) with increased latency period due to decreased liquor volume. Puerperal pyrexia increased proportionally with latency maximum $37.5 \%$ cases had pyrexia after 72 hours latency. Table no. 2 .

\begin{tabular}{|c|l|c|c|c|c|}
\hline S. No. & Maternal Morbidity & <24 hrs. & $\mathbf{2 5 - 4 8}$ & $\mathbf{4 9 - 7 2}$ & $>\mathbf{7 2}$ \\
\hline 1. & Chorioamnionitis n=5 & 0 & $1(20 \%)$ & $1(20 \%)$ & $3(60 \%)$ \\
\hline 2. & Abruption n=8 & 0 & $2(25 \%)$ & $2(25 \%)$ & $4(50 \%)$ \\
\hline 3. & PPH n=6 & $03(50.0)$ & $03(50 \%)$ & 0 & 0 \\
\hline 4. & Puerperal Pyrexia n=16 & $1(6.2 \%)$ & $4(25.0 \%)$ & $5(31.2 \%)$ & $6(37.5 \%)$ \\
\hline \multicolumn{4}{|c|}{ Table No. 2: Maternal morbidity in relation to latency } \\
\hline
\end{tabular}

$$
\chi 2=16.059 \quad \text { Degree of freedom }=9 \quad \mathrm{p}<0.0657 \text { Not significant }
$$

Perinatal Complications: In present study out of total neonatal morbidities and comorbidities, most common mortality was respiratory distress syndrome (RDS) in 30.0\%, neonatal sepsis (NNS) in $20.0 \%$, while that of pneumonia, necrotizing enterocolitis (NEC), intraventricular hemorrhage (IVS) were 5.0\%, 2.5\%, 2.5\% respectively. table no. 3

\begin{tabular}{|c|c|c|c|c|c|}
\hline & n=64 RDS & n=40 NNS & n=10 Pneumonia & n=5 IVH & n=5 NEC \\
\hline $28-30(\mathrm{n}=53)$ & $46(86 \%)$ & $26(49 \%)$ & $6(11.3 \%)$ & $3(5.6 \%)$ & $5(9.4 \%)$ \\
\hline $31-33(\mathrm{n}=67)$ & $14(20.8 \%)$ & $10(14.9 \%)$ & $2(2.9 \%)$ & $2(2.9 \%)$ & 0 \\
\hline $34-36(\mathrm{n}=80)$ & $4(5 \%)$ & $4(5 \%)$ & $2(2.5 \%)$ & 0 & 0 \\
\hline \multicolumn{7}{r}{ Table No. 3: Relation of GA to Neonatal morbidities } \\
\hline
\end{tabular}

$\chi 2=6.003 \quad$ Degree of freedom $=8 \quad \mathrm{p}<0.646$ Not significant

Most of neonatal morbidities were found at 28-30 weeks gestation, RDS in 46 (86.0\%), neonatal sepsis in $26(49.0 \%)$ and pneumonia in $6(11.3 \%)$ babies while at 34-36 weeks respiratory distress syndrome in $4(5.0 \%)$, neonatal sepsis in $4(5.0 \%)$, pneumonia in $2(2.5 \%)$ babies. Number of babies with low Apgar score who also required advanced resuscitation was 52.0\%. Neonatal death occurred in $1.5 \%$ babies having Apgar score $<3$ at $5 \mathrm{~min}$.

In this study 95\% were live births and 5.0\% were still births. All 190 live babies were admitted in NICU, out of them $14.2 \%$ were neonatal deaths and $86.0 \%$ survived. Maximum still birth $44.4 \%$ and neonatal death $22.2 \%$ were babies of $\leq 1 \mathrm{~kg}$ but with increasing birth weight survival rate increased to $100 \%$ for babies of $>2.5 \mathrm{~kg}$ and no still birth, neonatal death found. table no. 4 . 


\begin{tabular}{|c|c|c|c|c|}
\hline S.No. & Birth Weight & $\begin{array}{c}\text { SB } \\
\mathbf{n = 1 0}\end{array}$ & $\begin{array}{c}\text { NND } \\
\mathbf{n = 2 1}\end{array}$ & $\begin{array}{c}\text { Survival } \\
\mathbf{n = 1 6 9}\end{array}$ \\
\hline 1. & $\leq 1 \mathrm{~kg}=9$ & $4(44.4)$ & $2(22.2)$ & $03(33.33)$ \\
\hline 2. & $1.1-1.5=53$ & $4(7.5)$ & $13(24.5)$ & $36(67.9)$ \\
\hline 3. & $1.6-2=66$ & $1(1.5)$ & $6(9.0)$ & $59(89.3)$ \\
\hline 4. & $2.1-2.5=63$ & $1(1.5)$ & 0 & $62(98.4)$ \\
\hline 5. & $>2.5=9$ & 0 & 0 & $09(100.0)$ \\
\hline
\end{tabular}

Table no. 4: Neonatal outcome according to birth weight $(n=200)$

$\chi 2=63.444$

Degree of freedom $=8$

$\mathrm{p}<0.0001$ Significant

Maximum still birth (11.3\%) and neonatal death 24.5\%were in babies belonging to 28-30 weeks of gestation but with increasing gestational age survival increased to $98.75 \%$ at $34-36$ weeks of gestation with no neonatal death. table no. 5 .

\begin{tabular}{|c|c|c|c|c|}
\hline S.No. & Gestational age & $\begin{array}{c}\text { SB } \\
\mathbf{n = 1 0}\end{array}$ & NND n=21 & Survival n=169 \\
\hline 1. & $28-30=53$ & $6(11.3 \%)$ & $13(24.5 \%)$ & $34(64.15 \%)$ \\
\hline 2. & $31-33=67$ & $3(4.4 \%)$ & $8(11.9 \%)$ & $56(83.5 \%)$ \\
\hline 3. & $34-36=80$ & $1(1.25 \%)$ & 0 & $79(98.75 \%)$ \\
\hline \multicolumn{5}{|c|}{ Table No. 5: Neonatal outcome according to GA (n=200) }
\end{tabular}

$\chi 2=29.514$

Degree of freedom $=4$

$\mathrm{p}<0.0001$ Significant

DISCUSSION: Most Studies found higher incidence of PPROM 68.8\% in women belonging to low socioeconomic status. In study by Arij Faksh Doa et $\mathrm{al}^{2}$ incidence of PPROM was 64.5\% in primigravida, $17.8 \%$ in gravida II and $17.75 \%$ in multi gravida. While in study by Joelle M Lieman et $\mathrm{al}^{3}$ found $43 \%$ women with PPROM were primigravida, incidence of PPROM was $7.2 \%$ in which $48.8 \%$ cases were between $34-36,26 \%$ between $31-33$ weeks, $14.4 \%$ between $28-30$ weeks, $3.4 \%$ at 27 weeks and $7.2 \%$ at less than 26 weeks.

Hannah ME et al ${ }^{4}$ studied patients at term and revealed that $95 \%$ of patients delivered within one day of PROM.

Study by Tahir, Aleem M et $\mathrm{al}^{5}$ cesarean section rate was $14 \%$ whereas in study by Fatemeh Tauassoli et al ${ }^{6}$ cesarean section rate was $32.0 \%$.

Prospective study by Fatemeh Tauassoli et $\mathrm{al}^{6}$ had incidence of chorioamnionitis $5 \%$ and that of placental abruption was $5.8 \%$ which is close to present study. Women at high risk of infection because of membrane rupture, prolonged labor and multiple cervical examinations have 5-6\% incidence of metritis after vaginal delivery. If there occurs intrapartum chorioamnionitis risk of persistent uterine infection increases to $13 \%{ }^{7}$.

Mercer $\mathrm{BM}$ et $\mathrm{al}^{8}$ in their study demonstrated significant reduction in the incidence of chorioamnionitis (11\%) in the women with immediate delivery following PPROM as compared with those in expectant management group (28\%). 
Sims EJ et $\mathrm{al}^{9}$ reported $17 \%$ rate of RDS in neonates with maternal PPROM. Incidence of RDS in present study was higher. This result may be effect of higher rates of neonatal survival when delivery occurred at an earlier gestational age possibly indicating that the complications witnessed were related more closely to the effect of preterm birth rather than PPROM.

Joelle $\mathrm{M}$ et $\mathrm{al}^{3}$ found that RDS was the most common major morbidity noted across each gestational age group. Its incidence along with composite major neonatal morbidities was significantly higher among pregnancies delivered at 33 wks. or less weeks of gestation after PPROM as compared with those who delivered at 36 weeks.

In study by Taylor and Graite ${ }^{10}$ Perinatal mortality was $25 \%$ while in present study perinatal mortality was $10.5 \%$ which is comparable to reported by Multer et al ${ }^{11}$. This is most likely as a result of use of antenatal antibiotics, corticosteroid and improved neonatal care. Another reason could be that in previous studies gestational age at onset of PPROM was taken remote from viability to 32 weeks.

In retrospective study of Lee $\mathrm{C}$ Yang et $\mathrm{al}^{12}$ perinatal survival based on gestational age at onset of PROM was $12.1 \%$ at $<23$ wks., $60 \%$ at 23 weeks and $100 \%$ in $24-26$ weeks gestational age group.

CONCLUSION: PPROM is one of the important causes of preterm birth that can result in high perinatal morbidity \& mortality along with maternal morbidity. Looking after a premature infant puts immense burden on the economy and health care resources of the country. Therefore management of PPROM requires accurate diagnosis and evaluation of the risks and benefits of continued pregnancy or expeditious delivery. An understanding of gestational age dependent neonatal morbidity and mortality is important in determining the potential benefits of conservative management of preterm PROM at any gestation. It is important that the patient should be well informed regarding the potential for subsequent maternal, fetal and neonatal complications regardless of the management approach. Risk scoring strategies involving the demographic variable along with previous history of preterm deliveries should be developed to identify high risk cases and treating them prior to rupture of membrane.

\section{REFERENCES:}

1. Arias F, Tomich PH. Etiology and outcome of low birth weight and preterm infants. Obstet Gynaecol 1982; 60:277-.81.

2. Arij Faksh, Joseph R. Wax, F. Leelucas, Angelina Castina, Michael G. Pinette. Preterm premature rupture of membranes $\geq 32$ weeks' gestation: impact of revised practice guidelines American Journal of Obstetrics and Gynecology Vol. 205, Issue 4, Oct. 2011. Pages 340 e1 - 340 e5.

3. Joelle M. Lieman, Cynthio G. Brunfield, Walderman Carlo and Patrick S. Ramsey. Preterm premature rupture of membranes: Is there an optimal gestational age for delivery? ACOG. Vol. 105, No. 1, Jan. 2005.

4. Hannah ME, Ohlesson A, Farine $\mathrm{D}$ et al. Induction of labor compared with expectant management for prelabor rupture of membranes at term. N Engl J Med 1996; 334:1005-10.

5. Tahir, Aleem M, Aziz R. Incidence and outcome of preterm premature rupture of membranes. Pak J. Med. Sci. 2002; 18(1): 26-32. 
6. Fatemeh Tauassoli, Mazzieh Ghasemi, Ashraf Mohamadzade, Jamileh Sharifian. Survey of pregnancy outcome in preterm premature rupture of membranes with amniotic fluid index $<5$ and 5. Oman Medical Journal 2010 Vol. 25 Issue 2, April 2010.

7. Maberry MC, Gilkstropic, Bawdon RE et al. Anaerobic coverage for intra amniotic infection. Maternal \& Perinatal impact. Am. J. Perinatal 8:338, 1991.

8. Mercer BM, Crocker L, Beon et al. Induction versus expectant management in premature rupture of the membranes with mature amniotic fluid at 32 to 36 weeks: a randomized trial. Am. J. Obst. Gyne. 1993; 82: 775-82.

9. Sims EJ, Vermillon ST, Soper DE. Preterm premature rupture of the membranes is associated with a reduction in neonatal respiratory distress syndrome. Am J Obst Gynecol. 2002; 187: 268272.

10. Taylor J, Garite TJ. Premature rupture of membranes before fetal viability. Obst Gynecol. 1984; 64: 615-620.

11. Multer H, Briese V, Nagal H. Expected management of premature rupture of foetal membranes before 35 completed weeks of pregnancy. A retrospective analysis of 44 cases, ZentralbeGyna. 1994; 116(8): 479-83.

12. Lee C Yang, Donald R.Taylor, Howard H. Kaufman, Roderick Hume, Byron Calhour. Maternal and Fetal Outcomes of Spontaneous Preterm Premature Rupture of Membranes. J Am Osteopath Assoc. December 1, 2004 vol. 104no. 12 537-542

\section{AUTHORS:}

1. Padma Shukla

2. Meena Bhargava

3. Disha

\section{PARTICULARS OF CONTRIBUTORS:}

1. Assistant Professor, Department of Obstetrics \& Gynaecology, Shyam Shah Medical College, Rewa (M.P.)

2. Head of the Department, Department of Obstetrics \& Gynaecology, Shyam Shah Medical College, Rewa (M.P.)

3. Post Graduate, Department of Obstetrics \& Gynaecology, Shyam Shah Medical College, Rewa (M.P.)

\section{NAME ADDRESS EMAIL ID OF THE CORRESPONDING AUTHOR:}

Dr. Padma Shukla, 12/145, Swapnil, Khutethi, Rewa (M.P.)

E-mail: shukladrpadma@gmail.com

Date of Submission: 14/01/2014. Date of Peer Review: 15/01/2014. Date of Acceptance: 30/01/2014. Date of Publishing: 17/02/2014. 